\title{
Repercussões do plano nacional de formação dos professores da educação básica (PARFOR) no processo de formação docente sob o olhar do estudante de pedagogia
}

\author{
Cristina Zukowsky Tavares' \\ Elize Keller-Franco ${ }^{2}$ \\ Dayse Karoline de Carvalho ${ }^{3}$ \\ Catherine Oliveira de Araújo ${ }^{4}$ \\ Elnaque Ribeiro Costa Leite ${ }^{5}$
}

Resumo: O estudo propõe avaliar a repercussão do Plano Nacional de Formação dos Professores da Educação Básica (PARFOR) na formação docente de concluintes do curso de pedagogia de um Centro Universitário em São Paulo. O estudo de natureza qualitativa teve como instrumento de coleta de dados um questionário que envolveu questões abertas objetivando caracterizar o perfil dos participantes, suas perspectivas profissionais, contribuições recebidas em processo e encaminhamentos que realizam ao curso formador. Para a análise dos dados, as respostas dos participantes foram organizadas em três eixos temáticos que passaram a nortear a discussão dos resultados da pesquisa em diálogo com a literatura específica da área. Os resultados expressam contribuições da formação na visão de mundo e educação dos pesquisados, destacando-se também a satisfação com o reconhecimento e valorização profissional almejado ao receberem o título de "professores".

\footnotetext{
1 Doutora em Educação (Currículo) pela PUC-SP. Estudos Pós-Doutorais pela Unifesp e pela USP. Docente no Programa de Mestrado em Promoção da Saúde no Centro Universitário Adventista de São Paulo (Unasp). E-mail: cristina.tavares@unasp.edu.br

2 Doutora em Educação (Currículo) pela PUC-SP. Docente no Programa de Mestrado Profissional em Educação do Centro Universitário Adventista de São Paulo (Unasp). E-mail: elize.franco@unasp.edu.br

3 Mestra em Educação pela PUC-SP. Coordenadora do Curso de Pedagogia do Centro Universitário Adventista de São Paulo (Unasp). E-mail: dayse.carvalho@unasp.edu.br

4 Doutora em Distúrbios do Desenvolvimento pela Universidade Presbiteriana Mackenzie.

Coordenadora de Pós-graduação e Professora no Curso de Pedagogia do Centro Universitário Adventista de São Paulo (Unasp). E-mail: catherine.oliveira@unasp.edu.br

5 Doutoranda em Educação pela Universidade Estadual de Campinas (Unicamp). Professora no Curso de Pedagogia do Centro Universitário Adventista de São Paulo (Unasp). E-mail: elnaque.leite@unasp.edu.br
} 
Palavras-chave: PARFOR; pedagogia; formação docente

\title{
Repercussions of the national training of basic education teachers plan (PARFOR) in the professional formation of teacher- sunder the view of education students
}

\begin{abstract}
The study aims to assess the impact of the National Training of Basic Education Teachers Plan (PARFOR) in teacher training of senior year students of the education school at a University Center in São Paulo. The qualitative study collected data through a questionnaire containing opened questions aimed to characterize the profile of the participants, their professional perspectives, contributions received during the process and referrals performed in the trainer course. For the data analysis, the answers of the participants were organized in three themes that guided the discussion of the results under the light of specific literature. The results show that the training contributed to enhance the worldview and education of the participants, highlighting the awaited satisfaction from social recognition and professional development after receiving the title of "teacher."
\end{abstract}

Keywords: PARFOR; pedagogy; teacher education

Avaliar a repercussão de um projeto de formação que se veicula no desenho de um currículo de formação de professores não é pauta para debates secundários. Como formadores de opinião, os docentes que atuam a partir dos primeiros anos de escolarização de uma criança poderão simplesmente reproduzir dados, fatos e informações numa perspectiva de transmissão mecânica de conhecimentos acumulados ao longo de gerações, ou poderão fomentar o pensamento, a reflexão e a possibilidade de apropriação crítica de conhecimentos, além da construção de novas experiências e conceitos contextualizados com as necessidades educacionais e sociais de determinado tempo e espaço. Pensar a educação como direito fundamental de todas as pessoas, para estas que possam exercer sua vida política e cidadã com naturalidade e dignidade, é também pensar o perfil profissional do educador necessário para uma sociedade em busca de qualidade de vida para um número cada vez maior de pessoas,

Os novos contextos sociais levam à necessidade de se ter em mente que a educação - que é um direito humano e é um bem público - é que permite às pessoas exercer os outros direitos humanos e, assim, ela é essencial na compreensão, conscientização, demanda e luta por esses direitos. Evidencia-se hoje na vida social, no trabalho, nas relações interpessoais, como apropriar-se de conhecimentos se torna cada vez mais necessário, uma vez que conhecimento é um dos determinantes de desigualdades sociais. Ele se mostra como princípio diferenciador 

no processo de formação docente sob o olhar do estudante de pedagogia

de pessoas e grupos humanos e, se queremos uma sociedade justa, precisamos de uma escola justa. Uma escola que propicie a todos saber tratar, interpretar e formar juízos independentes sobre conhecimentos e informações (GATTI, 2013, p. 53).

Avaliar a formação inicial de profissionais do magistério matriculados em diferentes Instituições de Ensino Superior, públicas e privadas, é fundamental para que se possa pensar e refletir em ações que impliquem retomada, melhoria e aperfeiçoamento dos planos e programas educacionais em curso, tendo em vista sua qualidade científica, profissional e social. Considerando a avaliação da formação vivida em um curso como um processo de levantamento de indicadores e resultados, acreditamos que oportunizar a vez e a voz de graduandos no processo final de seu percurso de formação possa trazer dados pertinentes ao debate e à possibilidade de planejar estratégias de intervenção em processo. Scheibe (2010), ao tecer considerações sobre a valorização e formação dos professores da educação básica, defende que o processo avaliativo em nossos espaços de formação no Brasil pode ser regido por critérios mais amplos, uma vez que procedimentos avaliativos são essenciais para a melhoria de nossas políticas, planos, projetos e currículos de formação.

A partir de uma autoavaliação institucional, em todos os sistemas de ensino, com critérios definidos nacionalmente, podem ser identificadas, por exemplo, lacunas na formação inicial, passíveis de serem sanadas pelo desenvolvimento de um programa de formação continuada, assim como aspectos com potencial para a melhoria dos profissionais de educação. Para que, efetivamente, contribua para a formação e a valorização profissional, o processo avaliativo requer um caráter participativo, fundamentado em princípios éticos, democráticos, autônomos e coletivos (SCHEIBE, 2010, p. 994-995).

Imbuídos da necessidade de avaliar a repercussão da formação vivida e planejar reestruturações e melhorias de forma mais consciente é que iniciamos o procedimento de investigação e percepção dos anos de estudos e práticas de concluintes de um curso de Pedagogia oferecido em um Centro Universitário da cidade de São Paulo, que abrigou, a partir de 2011, um grupo de 91 graduandos matriculados no Plano Nacional de Professores da Educação Básica (PARFOR). O curso de Pedagogia PARFOR desta IES, de natureza presencial, foi concebido com tempos de formação distribuídos em 20 horas semanais ao longo de quatro anos, e com um desenho curricular inovador na perspectiva de um currículo integrado em que as disciplinas isoladas foram agrupadas em ciclos temáticos semestrais de formação e inserção na realidade educacional. Cada ciclo foi constituído por módulos e agregou componentes curriculares afins numa perspectiva de trabalho interdisciplinar (KELLER-FRANCO; BESSA, 2017).

Bernardete Gatti $(2011,2013)$ nos relembra que, no século passado, Fernando de Azevedo já apregoava, no discurso inicial do Manifesto dos Pioneiros da Escola Nova, o desafio da formação docente para a escola básica, questão muitas vezes tratada com descuido. Assim, não é de hoje a preocupação com a formação de docentes preparados adequadamente para pensar, refletir e agir propositadamente diante dos inúmeros desafios que a sociedade e escola básica contemporânea nos impõem. 

no processo de formação docente sob o olhar do estudante de pedagogia

Em 1932, se propunha uma formação universitária para todos os professores da educação básica" e esforços na direção de "criar para os docentes uma identidade profissional fundada na formação em nível superior, mas uma formação densa erigida a um alto nível cultural-científico (GATTI, 2013, p. 57).

A autora ainda pondera que do Manifesto (1932) para cá pouco caminhamos em qualidade. Na verdade, embora desde 1996 a Lei de Diretrizes e Bases (LDB) da Educação Nacional (Brasil, 1996) preconize oficialmente a formação de todos os professores em nível superior, e que inúmeras pesquisas tenham sido empreendidas na tentativa de compreender essa realidade e propor alternativas, os resultados muitas vezes parecem indicar que há necessidade de um maior número de ações no enfrentamento da complexa realidade educacional brasileira de ensino e formação.

No Brasil, vários encaminhamentos contribuíram para a complexidade da formação dos professores - culturais, políticos, econômicos, técnicos ou mesmo subjetivos. De um lado, a crescente expansão de oferta na educação básica e as possibilidades de inclusão social, com o atendimento de estratos sociais até recentemente pouco atendidos no segmento escolar, provocou a demanda por professores em todos os níveis da escolarização. Por outro, a modernização das sociedades e mudanças de todas as ordens adentraram os muros da escola exigindo uma formação que considere a construção de uma sociedade mais justa e democrática (SILVA et al., 2013).

Um dos caminhos propostos para a expansão da formação dos professores brasileiros foi o Decreto n 6.755, aprovado em 29 de janeiro de 2009, que trata da Política Nacional de Formação de Profissionais do Magistério da Educação Básica. À Coordenação de Aperfeiçoamento de Pessoal de Nível Superior (CAPES) coube a gestão e fomento de programas de formação inicial e continuada para a rede pública de educação básica em colaboração entre União, Estados, Distrito Federal e Municípios. Os artigos desse decreto explicitam finalidades, diretrizes e objetivos dessa política de formação que, com certeza, mostrou-se ousada diante de tamanhos desafios a transpor. Para o cumprimento desses objetivos foram criados Fóruns Estaduais Permanentes de apoio à Formação Docente, em regime de colaboração entre os distintos entes federais, estaduais, municipais e ações específicas do Ministério da Educação (CASTRO, 2010).

Três meses depois da promulgação desse Decreto, no dia 28 maio de 2009, foi lançado o Plano Nacional de Formação de Professores da Educação Básica (PARFOR) e, em 30 de junho do mesmo ano, por meio da Portaria Normativa n 9, o Plano PARFOR foi instituído oficialmente pelo Ministério da Educação (MEC), com ações definidas em acordos de cooperação técnica do MEC, por intermédio da CAPES e das Secretarias de Educação. Essas ações visavam organizar a formação dos professores das redes públicas, levando em consideração dados do censo escolar 2007, que registraram 600.000 professores atuando no Ensino Básico público brasileiro sem a formação adequada ao seu foco de atuação e às exigências da Lei de Diretrizes e Bases (LDB/96). Como bem elucida Bernardete Gatti, 

no processo de formação docente sob o olhar do estudante de pedagogia

O PARFOR (Brasil, 2009) compreende um conjunto de ações do MEC em colaboração com as secretarias de educação de estados e municípios e Instituições de Ensino Superior (IES) públicas para ministrar cursos superiores a professores em exercício em escolas públicas que não possuem a formação adequada prevista pela LDB. Esses cursos podem ser uma primeira licenciatura, para os que não possuem graduação, ou segunda licenciatura, para os licenciados atuando fora da área de formação, e também cursos de Formação Pedagógica para bacharéis sem licenciatura. Ações apoiadas nesse Plano são encontradas bem disseminadas pelos estados e em muitos municípios, em associação com universidades públicas. As potencialidades do PARFOR são consideradas grandes por especialistas que analisaram experiências sob sua égide (GATTI, 2013, p. 61).

Formar professores por meio desse Programa emergencial do Governo Federal mostrou-se como uma possibilidade que poderia servir aos objetivos originais se a parceria entre os entes federados e instituições universitárias demandassem comprometimento, planejamento e avaliação. É por isso que nos voltamos, nessa investigação, para uma das células de atuação do PARFOR em um Centro Universitário da cidade de São Paulo, buscando questionar os concluintes desse processo de formação, tendo em vista as reorientações necessárias que ocorrem em um processo formativo em avaliação ou mesmo os encaminhamentos que podem acompanhar os resultados de uma pesquisa.

\section{Metodologia}

A investigação de natureza qualitativa buscou flagrar opiniões, percepções, significados, sonhos e sugestões dos graduandos em Pedagogia vinculados ao Plano Nacional de Formação de Professores da Educação Básica (PARFOR). O curso de Pedagogia na Instituição de Ensino Superior (IES) pesquisada, consciente de sua função social, aderiu ao PARFOR, assumindo o compromisso com a formação de professores.

No Campus São Paulo dessa IES, quatro turmas de Pedagogia PARFOR totalizavam 91 professores estudantes. $O$ primeiro grupo estava distribuído em três turmas (duas noturnas e uma vespertina) que tiveram início em fevereiro de 2011; no momento da pesquisa, em 2014, cursavam o $8^{\circ}$ período. 0 segundo grupo compôs uma única turma que iniciou em agosto de 2011 e no momento da pesquisa estavam no $6^{\circ}$ semestre. A amostra incluiu todos os estudantes PARFOR matriculados nesse campus da IES. Mesmo com algumas faltas ou alunos de licença no dia da aplicação do instrumento de coleta de dados foi possível reunir 83 respostas ao questionário, o qual era composto de questões abertas sobre a caracterização do perfil dos participantes, suas perspectivas profissionais, contribuições recebidas em processo e sugestões que ofereceriam ao curso formador. Para a análise temática das informações preliminares, os dados sobre o perfil dos estudantes foram organizados em planilha Excel para posterior levantamento do público geral. As demais respostas foram organizadas em quadros, um para cada pergunta. 

no processo de formação docente sob o olhar do estudante de pedagogia

Esse corpo de respostas constituiu as unidades temáticas que foram estudadas em um segundo momento e, a partir dos registros mais expressivos, organizamos as respostas dos participantes em três eixos temáticos - "Contribuições do curso", "Perspectivas/ Sonhos" e "Sugestões" - que passaram a nortear a discussão dos resultados da pesquisa em diálogo com a literatura específica da área. As respostas dos pesquisados foram catalogadas por meio de designações alfa numéricas de P1 até P83. Procuramos preservar ao máximo a escrita dos participantes nas unidades de registro da análise temática.

\section{Discussão dos resultados}

\section{Perfil dos participantes da pesquisa}

Dentre os participantes da pesquisa, 80 pertencem ao sexo feminino e apenas 3 ao sexo masculino. Os dados revelam mais uma vez a predominância feminina nas salas de aula da educação infantil e séries iniciais no Brasil, excluindo muitas vezes desse período de formação da criança uma participação masculina que poderia trazer um novo olhar e contribuição à educação dessa faixa etária. A Tabela 1 apresenta a distribuição dos estudantes PARFOR em formação na IES por municípios e escolas de Educação Infantil e Ensino Fundamental I.

Tabela 1 - Porcentagem de escolas com estudantes PARFOR em relação ao total de escolas no município.

\begin{tabular}{lccc}
\multicolumn{1}{c}{ Municípios } & $\begin{array}{c}\text { Total de escolas } \\
\text { no município }\end{array}$ & $\begin{array}{c}\text { Escolas com } \\
\text { pedagogos } \\
\text { PARFOR }\end{array}$ & $\begin{array}{c}\text { Pedagogos PARFOR / } \\
\text { número de escolas } \\
\%\end{array}$ \\
\hline Embu das Artes & 81 & 16 & $20 \%$ \\
\hline São Lourenço da Serra & 14 & 3 & $21 \%$ \\
\hline Juquitiba & 11 & 1 & $9 \%$ \\
\hline Itapecerica da Serra & 68 & 4 & $6 \%$ \\
\hline Carapicuíba & 57 & 1 & $2 \%$ \\
\hline Embu Guaçu & 35 & 4 & $11 \%$ \\
\hline São Paulo (Regional Sul 1 e 2) & 256 & 7 & $3 \%$ \\
\hline Total & 522 & 36 & $7 \%$ \\
\hline
\end{tabular}

Fonte: elaborado pelo autor

Os dados apresentados na Tabela 1 indicam que o município de Embu das Artes congrega o maior de número de escolas com professores/estudantes (PARFOR) em serviço, totalizando sessenta $(72,5 \%)$ dos oitenta e três alunos pesquisados. Dentre os demais, sete trabalhavam em São Paulo (8,5\%), cinco alunos (6 \%) em Embu Guaçu, cinco alunos (6\%) em Itapecerica, quatro alunos em São Lourenço da Serra (5\%), um aluno em Juquitiba (1\%) e também um em Carapicuíba (1\%). Outro dado 

no processo de formação docente sob o olhar do estudante de pedagogia

relevante é que 64 (77\%) dos 83 alunos pesquisados trabalham em escolas públicas de educação infantil, enquanto 19 pedagogos em formação (23\%) atuam no Ensino fundamental.

A concentração de idade dos concluintes PARFOR encontra-se entre 35 anos (25\%) e 55 anos (25\%), tendo os pesquisados, em geral, muitos anos de experiência em sala de aula, mas sem a formação em ciências da educação que permite uma leitura mais ampla dos desafios educacionais. Muitos desses graduandos residem em um município e trabalham ou estudam em outro, o que demanda grande esforço na racionalização do tempo e administração do cansaço físico e mental. Sendo o grupo predominantemente feminino, a maioria dos estudantes ainda acumulam responsabilidades caseiras no cuidado da família e educação dos filhos e netos. Muitos ainda são o suporte financeiro do lar, sendo que o salário de auxiliares de ensino é muito próximo de um salário mínimo brasileiro em 2014. Dessa forma, observamos que o Plano de Formação do Governo Federal veio colaborar com esse grupo de profissionais que por muitos anos não tiveram a possibilidade da formação superior em Pedagogia.

Praticamente todos os participantes do grupo PARFOR pesquisado atuam na função de Auxiliares de Desenvolvimento Infantil (ADI) - alguns no Ensino Fundamental nível I e poucos no Fundamental nível II, estes últimos por estarem cursando a segunda licenciatura. Assim, a possibilidade de em breve portar o diploma de Licenciados em Pedagogia outorga à maioria o direito de exercer a sua profissão de forma mais plena, sendo a partir de então designados "professores", podendo, no plano de carreira, ter melhor reconhecimento social, econômico e profissional.

\section{Contribuições do Curso: aspectos conceituais e atitudinais}

Em termos conceituais e atitudinais, os graduandos expressam principalmente observar mudanças no que diz respeito à formação de uma visão de mundo e educação capaz de nortear e fundamentar crítica e eticamente sua prática pedagógica e, em alguns momentos, ressignificá-la ou mesmo transformá-la:

- "Tive um entendimento da construção do conhecimento em ação conjunta do professor e aluno" (P46);

- "O entendimento de como se dá o conhecimento da criança na criança, a forma como ela aprende e interage com esse conhecimento" (P16);

- "Tenho pouco tempo como docente e aproveitei para unir a teoria com a minha prática" (P20);

- "Sei agora acompanhar por meio de jogos o nível do raciocínio lógico-matemático, pensar em estratégias para alfabetizar e avaliar o aprendizado do aluno" (P23);

- "Aprendi a praticar a teoria, muitas vezes sabíamos a prática e não a teoria que hoje pensamos junto" (P29); 
Repercussões do plano nacional de formação dos professores da educação básica (PARFOR) no processo de formação docente sob o olhar do estudante de pedagogia

- "Agreguei a prática à teoria de forma mais clara e objetiva" (P32);

- “Com o magistério (nível médio de formação) já sou professora há 7 anos e tenho mais 8 anos como auxiliar de desenvolvimento infantil (ADI), tudo na mesma rede de Embu das Artes. Porém, foi na faculdade que aprendemos O PORQUÊ dessa prática na teoria" (P33);

- "Tive conhecimento sobre as teorias da educação e suas concepções pedagógicas e filosóficas" (P37);

- "Exercer coerência com o que aprendi e o que já sabia na prática" (P51);

- "Mais responsabilidade e interesse em buscar novos conhecimentos" (P54);

- "Mudei alguns conceitos já impregnados que não auxiliavam no desenvolvimento dos alunos" (P17);

- "Passei a compreender e valorizar o aluno em todos os aspectos de forma integral, com respeito, ética, amor à profissão" (P23);

- "Mudei conceitos sobre religião, sobre como lidar com as pessoas e comigo" (P30);

- "Mudei a postura agregando valores como cooperação e solidariedade, outra visão de mundo" (P35);

- "Aqui me tornei mais solidária" (P24);

- "Aprendi a lidar com certos problemas com maior clareza com base no ensino religioso que tivemos" (P29);

- "Melhorou meu modo de pensar e conceber o ser humano" (P27);

- "Mudou muito minha visão de sala de aula e escola" (P49);

- "Formei uma cosmovisão com valores e princípios perenes" (P18);

- "Melhorei em valores profissionais e familiares" (P40);

- "Aprendi a interagir, respeitar a opinião dos outros, entender colegas de trabalho e alunos" (P56);

- "Integrei o conteúdo teórico aprendido às ações do dia a dia tanto no trabalho como na vida social" (P46);

- "Ampliei os conhecimentos abolindo práticas que não eram boas para dar espaço a coisas novas" (P10);

- "Mudei meu perfil de educadora" (P12).

- Algumas contribuições da formação obtida em termos procedimentais foram destacadas, como por exemplo:

- "Aprendi a fazer jogos, pesquisar e manusear o computador" (P24); 
Repercussões do plano nacional de formação dos professores da educação básica (PARFOR) no processo de formação docente sob o olhar do estudante de pedagogia

- "Aprendi a desenvolver melhor as redações e planos de aula" (P27);

- "Os vários procedimentos que foram ensinados aqui como sondagens, trabalho com jogos, até a forma de falar com a criança em certas situações" (P29);

- "Diversidade de estratégias e técnicas mais adequadas para desenvolver os conteúdos" (P50);

- "Aprendi que os jogos podem ser usados em diferentes áreas do conhecimento" (P31);

- "Tenho mais facilidade em planejar aulas, projetos e fazer interpretações de texto que antes era bem mais difícil" (P38);

- "Aprendi a fazer pesquisas e por meio delas eu aprendi a manusear e usar o computador nas minhas atividades" (P39);

- "Sei melhor desenvolver um artigo científico e plano de aula" (P40);

- "Aprendi a fazer projetos com as suas etapas e melhorar os meus planos de aula" (P41);

- "Metodologias conscientes de trabalho, seguindo o processo de evolução dos alunos" (P17);

- "Métodos inovadores e criativos para preparar aulas" (P55);

- "Métodos de ensino que vão de encontro com meus objetivos em educação. Envolvi outros colegas de trabalho em projetos para o melhor desenvolvimento das crianças" (P16);

- "Observar com olhar de pesquisador as crianças e as aulas em geral" (P52);

- "Aprendi a ler!" (P56).

- Ao serem convidados a explicitar de forma um pouco mais detalhada esse processo de mudança obtivemos declarações como:

- "Passei a avaliar minha postura como educadora. Estou utilizando o conhecimento adquirido para melhorar minha prática levando sempre em consideração o estágio de desenvolvimento da criança" (P61);

- "Aprendi a enxergar a criança de outra forma, a partir do conhecimento de suas fases de desenvolvimento; faço intervenções de forma mais adequada principalmente nos conflitos. Aprendi a estimular as crianças a avançar em seu desenvolvimento" (P2);

- "Mudei no critério de avaliar e me dirigir ao aluno integrando-o na aula e dando-lhe liberdade de se colocar sem medo de errar" (P17);

- "O curso de Pedagogia me auxiliou muito no trabalho. Aprendi a discutir e trabalhar com a equipe da escola, de igual para igual" (P3);

- "Ao longo do curso desenvolvi a capacidade de compreender e interpretar diferentes textos por meio da leitura" (P4); 

no processo de formação docente sob o olhar do estudante de pedagogia

- "Houve sim mudanças, principalmente no respeito entre os demais colegas de trabalho. Passaram a me dar mais oportunidade de me expressar perante os demais e mais atenção ao meu profissionalismo" (P15);

- "Minha visão em sala de aula ampliou, não os vejo só como alunos e sim como seres humanos. Os métodos que aprendi abriram um novo mundo, e não quero parar. Estudar é cansativo, mas é necessário" (P43);

- "Posso dizer que aprendi muito e algo que nunca tinha apreciado como os jogos matemáticos que estudamos [...] no estágio quando aplicado para as crianças elas adoraram. Seus rostinhos brilhavam de entusiasmo e alegria" (P44);

- "Ao iniciarmos o curso já desenvolvíamos nosso trabalho com competência. Porém tínhamos posturas não adequadas, vícios interiorizados da maneira como cada uma de nós aprendeu".

- "Após passarmos pelos bancos da universidade fomos nos despindo dessas posturas iniciais [...]. Hoje sei lidar e entender as crianças, trabalho com prazer e me sinto privilegiada em estar estudando" (P11);

- "Vejo a escola de forma mais ampla e o aluno como sujeito capaz de aprendizagem e desenvolvimento cognitivo" (P22);

- "Exerço minha profissão com mais segurança e confiança no trato com os alunos, com mais amor e dedicação, pois agora entendo melhor como funciona a sua mente" (P23);

- "Hoje a visão que eu tenho de educação é totalmente diferente e, por trabalhar na área, acredito que tenho mais autonomia para realizar determinadas tarefas que me competem" (P45);

- "Melhorei em todos os sentidos, na forma de falar, na escrita, nos procedimentos de aprendizagem usados com as crianças, ao planejar atividades na vida profissional e pessoal também" (P29);

- "Fazer a faculdade foi a melhor coisa que me aconteceu [...] surpreendente [...] conquistei uma nova maneira de pensar, expressar esse pensamento que também influenciou no meu agir" (P46).

\section{Perspectivas e sonhos para além do processo formador vivido}

Ao serem questionados a respeito do seu sonho em termos profissionais, os participantes declaram o interesse em fazer diferença no seu ambiente de trabalho como multiplicadores de aprendizagens vivenciadas. Alguns pensam em montar a própria escola de educação infantil e exercer funções de gestão no ambiente escolar. Expressam também o desejo de prestar novos concursos públicos que tragam melhorias em sua carreira profissional, todos na área da educação. Dentre os pesquisados, $40 \%$ desejam investir ainda mais na carreira profissional e acadêmica, continuando estudos de 

no processo de formação docente sob o olhar do estudante de pedagogia

pós-graduação e $5 \%$ manifestam o desejo de prosseguir sua especialização até a docência no Ensino Superior. Uma estudante também manifestou de maneira sincera o desejo de "continuar estudando e mudar de emprego" (P48).

As expressões dos participantes revelam as projeções que fazem para o futuro próximo e distante na ampliação dos estudos, no crescimento profissional, social e acadêmico:

- "Quero ser uma diretora" (P15);

- "Uma coordenadora/supervisora" (P52);

- "Tornar-me professora alfabetizadora" (P16);

- "Ajudar a mudar o sistema de ensino e auxiliar no desenvolvimento da autonomia dos alunos" (P17);

- "Partilhar o que aprendi com meus colegas e fazer a diferença na escola que trabalho"(P43);

- "Continuar a investir no meu aprendizado" (P45);

- "Exercer a profissão de professora" (P49);

- "A médio prazo, espero melhoria salarial e, alongo prazo, construir mais conhecimentos" (P50);

- "Montar a minha própria escola de educação infantil" (P54);

- "Continuar na área da educação" (P56);

- "Trabalhar na educação de jovens e adultos" (P09); "Ser um professor concursado" (P06); “Reconhecimento profissional” (P04);

- "Tornar-me professora no ensino superior" (P07);

- "Ser interprete em libras" (P11);

- "Continuar estudando... Mestrado, Doutorado"(P12);

- "Aprender sempre!" (P10).

O grande sonho desses estudantes de Pedagogia PARFOR, de maneira pontual, é receber, em curto prazo, o título oficial de professores da educação infantil e ensino fundamental I. O aumento da autoestima, a valorização e reconhecimento profissional e social tornam-se fundamentais. A partir da constituição sedimentada em novos construtos e conhecimentos, valores e concepções filosófico-pedagógicas, caminha-se em direção à profissionalização docente. 
Repercussões do plano nacional de formação dos professores da educação básica (PARFOR) no processo de formação docente sob o olhar do estudante de pedagogia

Não há consistência em uma profissionalização sem a constituição de uma base sólida de conhecimentos aliados a formas de ação. Donde a importância de uma sólida formação inicial, solidez também que necessita de reconhecimento pelo conjunto da sociedade. A representação de valor da profissão docente também está associada ao reconhecimento do valor social atribuído à sua formação. Com as formações oferecidas pelas instituições de ensino superior, como descrito, se está longe de atribuição social de valor para ela (GATTI, 2013, p. 60).

O reconhecimento salarial também abre novos horizontes aos docentes em formação que vislumbram dias melhores na constituição do status profissional e social, como vemos em Castro (2000, p. 789)

A questão do salário é fundamental para o aprimoramento da profissão de professor, uma vez que sem um bom salário não haverá motivação e sem perspectivas será difícil atrair os melhores alunos do ensino médio para o magistério. A questão salarial é um problema sério em nosso país, onde a profissão docente continua muito desvalorizada, se comparado seu piso com o valor do salário mínimo nacional, levando em consideração as exigências de formação e a jornada de trabalho do professor em relação àquelas de qualquer trabalhador sem nenhuma qualificação.

A autora segue ressaltando que, mais do que ações pontuais, precisamos refletir numa política de valorização e profissionalização da docência que contemple a formação inicial na graduação, a formação continuada, as condições de trabalho, o salário e plano de carreira do professor (CASTRO, 2010).

A pesquisadora Laurizete Passos (2012), ao apresentar a resenha do livro “Políticas Docentes no Brasil: um estado da arte", de Gatti, Barreto e André (2011), destaca por meio de estudos que a questão salarial e de carreira dos professores da educação básica é organizada pela análise de planos de carreira cedidos pelas Secretarias Estaduais e Municipais, e reúne dados das diferentes regiões do país. A avaliação indica que os ajustes em relação ao que a legislação tem determinado e em função das propostas em nível federal ainda não foram incorporados pelas legislações de muitos estados e municípios. Concluem, no entanto, que houve avanços significativos nos últimos anos havendo uma movimentação em torno dos planos de carreira nessas duas instâncias. Além disso, encontramos iniciativas recentemente constituídas que se encaminham na direção e intenção de,

valorizar o campo profissional, ainda que em patamares incipientes, tais como a Lei do Piso Salarial (Brasil, 2008) e, mais recentemente, as Diretrizes Nacionais para os Planos de Carreira e Remuneração dos Profissionais do Magistério da Educação Básica (Brasil/MEC/CNE, 2009). Contudo, é na formação docente que encontramos hoje o foco central das políticas nacionais ocorridas no cenário da educação brasileira desde a década de 1990. O professor, tido como agente de mudança, emerge, pois, cada vez mais, como o responsável pela realização do ideário do século XXI (SCHEIBE, 2010, p. 987).

Observa-se claramente um movimento, pelo menos por parte das instâncias federais de governo, de assegurar, no plano legal, maiores direitos e garantias aos professores de educação básica, o 
que poderia repercutir de alguma forma sobre a atratividade da carreira docente. Contudo, a carreira continua sendo matéria dos estados e municípios que a organizam segundo suas capacidades e a força política presente em cada local. Sabemos que "sem uma carreira estável que garanta as condições de trabalho e as relações de emprego dignas para os docentes, pouca eficácia terão os processos de avaliação e de formação para a melhoria almejada por esses governos para os sistemas públicos de educação" (OLIVEIRA, 2011, p. 36).

A educadora Iria Brzezinski (2014) critica a formulação de planos de programas de formação inicial de professores no Brasil, a qual ocorre ainda de maneira fragmentada, resultando rupturas e descontinuidades entre as propostas. Tal afirmação faz ecoar o pensamento de SOUZA (apud BRZEZINSKI, 2014) ao dizer que "não existe uma política pública global de formação e valorização dos profissionais da educação, de modo que se articule a qualidade social dos processos formativos com condições dignas de trabalho, carreira e planos de cargos e salários com base no piso salarial nacional".

\section{As sugestões dos graduandos participantes do PARFOR}

Os participantes da investigação também foram convidados a tecer considerações sobre o currículo e encaminhar sugestões ao aperfeiçoamento do processo de formação realizado pelo curso de Pedagogia. Muitos graduandos não quiseram emitir sugestões e declararam-se satisfeitos com o processo de formação vivido, eles acreditavam que nada deveria ser alterado, avaliando suas aulas como ativas e aptas ao bom desenvolvimento dos profissionais da educação. As sugestões colocadas referiram-se a:

- Aprofundar concepções filosóficas e linhas teóricas que fundamentam o ensino e a aprendizagem ao longo do percurso de formação;

- Um número maior de aulas dedicadas à elaboração do projeto e consecução da pesquisa de conclusão do curso;

- O cuidado quando se possui dois ou três professores conduzindo um módulo, pois, se não houver suficiente diálogo, pode haver dificuldades;

- Melhor planejamento dos módulos integrados do currículo;

- Mais aulas para aprendizagem de libras e, quem sabe, outro idioma;

- Ampliar ainda mais o número de estudos e pesquisas fundamentados na realidade da escola pública e aulas práticas;

- Alguns problemas de acesso ao espaço virtual de aprendizagem, alterações técnicas sem comunicação prévia ou excesso de trabalhos no ambiente virtual quando o tempo de sala de aula não é bem equacionado;

- Elaborar um manual para guiar o uso da informática educacional; 

no processo de formação docente sob o olhar do estudante de pedagogia

- Ampliar a vivência em escolas durante o período de formação;

- Reduzir as aulas optativas a partir do sexto semestre;

- Reduzir as aulas de seminários que, às vezes, se tornam muito repetitivas e com pouca atuação do docente;

- Cuidar para que as aulas não se tornem cansativas e pouco dinâmicas em alguns módulos em específico;

- Considerações sobre melhorias no espaço físico também, como carteiras, pinturas na parede.

Mesmo engajados em um modelo curricular diferenciado - o que favoreceu a construção de uma perspectiva mais integradora da educação - é importante estar atento a comentários de alguns alunos sobre a perda de diálogo entre os docentes, o que pode fazer com que haja brechas e rupturas no processo integrador e o aluno volte a solicitar a presença de um único docente por componente curricular, sob a perspectiva de currículos tradicionais de natureza segmentada e fragmentada. Ao analisar trabalhos de diferentes pesquisadores, Gatti (2013) evidencia inúmeras potencialidades do PARFOR em diferentes estados brasileiros, mas também algumas fragilidades na gestão organizacional e financeira das IES, bem como a necessidade de rever aspectos da organização curricular assumida pelas instituições parceiras, uma vez que essas são, em sua maioria, regidas por disciplinas tradicionais, sem inovação, com estrutura e conteúdos que não se adequam aos propósitos do Programa, especialmente ao se tratar de estudantes que já são professores em exercício. Dessa forma, critica currículos que não favorecem a prática reflexiva e a integração teoria-prática, que pode levar os alunos a fazerem associações dos aprendizados com suas experiências como docentes.

\section{Considerações finais}

$\mathrm{O}$ artigo aqui proposto para reflexão refere-se a um estudo realizado com graduandos vinculados ao Plano Nacional de Formação dos Professores da Educação Básica (PARFOR). Esse Plano, que surgiu como iniciativa política do Governo Federal, é resultado de um conjunto de ações do Ministério da Educação (MEC) por meio dos Fóruns Estaduais em colaboração com as Secretarias de Educação dos estados e municípios e das Instituições de Educação Superior neles sediadas, com fins à melhoria da formação do corpo docente brasileiro já em exercício nas escolas públicas. No entendimento de Souza (2014, p. 650) infere-se que na condução do PARFOR, mesmo diante de inúmeras assimetrias e conflitos regionais e institucionais, o Programa, de forma geral, "apresenta como produto a capacitação de professores em serviços por IES; como efeito, a profissionalização do professor pela obtenção da formação exigida pela lei n. 9.394 (Brasil, 1996); e, finalmente, como impacto, a melhoria da qualidade da educação básica". 

no processo de formação docente sob o olhar do estudante de pedagogia

Mesmo considerado um Plano emergencial de formação docente no contexto brasileiro e que precisava alcançar, a princípio, milhares de professores sem formação adequada à sua atuação em sala de aula nas escolas públicas, inferimos, pela experiência com aproximadamente cem professores em formação e profissionalização, que é possível avançar para outros patamares em nossas concepções e ações educacionais. Isso será é possível por meio do estudo e trabalho cooperativo entre Governo Federal, secretarias de estados e municípios, instituições parceiras de ensino superior públicas e privadas, escolas e professores, caso hajaengajamento e comprometimento de todos em favor da melhoria da qualidade da educação.

Ao objetivarmos trazer para a pauta de discussões a percepção dos participantes sobre o processo de formação vivido e a repercussão dessa formação em sua prática pedagógica cotidiana, os resultados expressaram uma contribuição relevante do curso de Pedagogia PARFOR em termos conceituais e atitudinais na formação de uma visão de mundo e educação que propiciem orientação e fundamentação crítica e ética para os futuros docentes, até mesmo ressignificando-a ou transformando-a. É notória a intenção de continuidade nos estudos (45\%) para além da graduação, o que acompanha a possibilidade de progresso na carreira profissional e um exercício docente mais consciente e significativo, não importando a idade em que começaram a cursar o Ensino Superior.

É relevante notar entre as sugestões dos alunos, dentre outros aspectos, que haja maior diálogo entre os docentes participantes de um módulo integrado do currículo, maior número de aulas voltadas à pesquisa e às linhas de pensamento filosófico aliadas à prática pedagógica na escola pública. Alguns mencionaram também alterações no espaço físico das salas de aula. Concluímos em todos os relatos que a maior conquista evidenciada pelos pesquisados reside no reconhecimento e valorização pessoal, profissional e econômico. Ao portarem seu diploma do Ensino Superior ou, para alguns, a segunda graduação , os auxiliares de ensino passarão a ser chamados "professores", o que altera substancialmente sua identidade como profissionais do ensino.

Mesmo com todos os conflitos vivenciados durante o período formador e os obstáculos que nunca se mostram pequenos, reforça-se cada vez mais a relevância dos processos formadores na conquista profissional e pessoal de espaços mais autônomos e alargados para exercício da docência e profissionalização no Brasil.

Com certeza, não podemos nos acomodar aos processos já vividos ou experiências exitosas já colhidas ou não. É preciso semear, muitas vezes até mesmo em terrenos ainda não explorados. Torna-se necessário ousar para expandir mais e melhor a formação para o tempo em que vivemos e com os novos desafios que se impõem.

Finalizamos enfatizando as palavras da pesquisadora Bernardete Gatti ao denunciar que ainda precisamos avançar, e muito, nos processos de formação. 
As políticas e as práticas relativas à formação inicial de docentes para a educação básica têm resistido há um século na conservação de uma estrutura curricular e institucional funcionando à margem dos movimentos socioculturais e históricos na atualidade, que evidenciam profundas mudanças na sociedade. A estrutura da educação básica mudou, os segmentos sociais que nela se inserem mudaram, a idade de inserção das crianças e adolescentes mudou. Essas mudanças exigem da formação de professores mudanças radicais (GATTI, 2013, p. 64).

Estaremos dispostos a enfrentar o desafio?

\section{Referências bibliográficas}

BRASIL. Decreto 6755, de 29 de janeiro de 2009. Política Nacional de Formação de Profissionais do Magistério da Educação Básica. Diário Oficial da União, Brasília, DF, jan. 2009.

BRASIL. Lei n. 12.056, de 13/10/2009: acrescenta parágrafos ao art. 62 da Lei no 9394, de 20/12/1996, que estabelece as diretrizes e bases da educação nacional.

BRASIL. Plano Nacional de Formação dos Professores da Educação Básica - PARFOR. Brasília, DF, 28/05/2009.

BRASIL. Portaria Normativa n.9, de 30/06/2009: institui o Plano Nacional de Formação dos Professores da Educação Básica no âmbito do Ministério da Educação.

Brasil. Fóruns Estaduais de apoio à formação docente: orientações para sua organização. Brasília, setembro, 2009.

BRASIL. Lei n. 9.394, de 20 de dezembro de 1996. Estabelece as diretrizes e bases da educação nacional. Diário Oficial da União, Brasília, DF, 23 dez. 1996.

BRASIL. Lei n. 10.172, de 9 de Janeiro de 2001. Aprova o Plano Nacional de Educação (2001-2010).

BRASIL. Ministério da Educação. Conselho Nacional de Educação. Resolução CNE/CEB n. 2, de 28 de maio de 2009. Fixa as Diretrizes Nacionais para os Planos de Carreira e Remuneração dos Profissionais do Magistério da Educação Básica Pública.

BRASIL. Ministério da Educação. Instituto Nacional de Estudos e Pesquisas Educacionais (INEP). Estudo exploratório sobre o professor brasileiro: com base nos resultados do Censo Escolar da Educação Básica 2007. Brasília, DF: MEC/INEP, 2009.

BRZEZINSKI, I. Sujeitos Sociais Coletivos e a Política de Formação Inicial e Continuada Emergencial de Professores: Contradições Vs Conciliações. Educação \& Sociedade, São Paulo, v. 35, n.129, out/dez 2014, p. 1241-1259.

CASTRO, M. Convergências e Tensões nas Propostas de 2009: Política Nacional de Formação de Profissionais do Magistério da Educação Básica e Plano Nacional de Formação de Professores. In: Dalben, Ângela I. L.de F. (et al.). Convergências e tensões no campo da formação e do trabalho docente. Textos selecionados do XV ENDIPE - Encontro Nacional de Didática e Prática de Ensino. Belo Horizonte: Autêntica, 2010.

GATTI, B A. A. Educação, escola e formação de professores: políticas e impasses. Educar em Revista, Curitiba, n. 50, out/dez 2013, p. 51-67. 
Repercussões do plano nacional de formação dos professores da educação básica (PARFOR) no processo de formação docente sob o olhar do estudante de pedagogia

GATTI, B. A.; BARRETO, E. S. S.; ANDRÉ, M. E. D. A. Políticas Docentes no Brasil: um estado da arte. Brasília: UNESCO, 2011.

KELLER-FRANCO, E.; BESSA, S. Construindo Alternativas para a Formação Inicial de Professores: a percepção de estudantes de pedagogia sobre a abordagem curricular integrada. Revista e-Curriculum, São Paulo, v. 15, n. 1, jan/mar 2017, p. 153-176.

PASSOS, L. F. Políticas Docentes no Brasil: Um Estado da Arte. Resenha. Caderno de Pesquisa, v. 42, n. 145, jan/abr 2012, p. 298-329.

SCHEIBE, L. Valorização e formação dos professores para a educação básica: questões desafiadoras para um novo plano nacional de educação. Educação e Sociedade, v. 31, n. 112, jul/set 2010, p. 981-1000.

OLIVEIRA, D. A. A nova regulação de forças no interior da escola: carreira, formação e avaliação docente. Revista Brasileira de Política e Administração da Educação, v. 27, n. 1, jan/abr 2011, p. 25-38.

SILVA, L. M.; BRIZOLLA, F.; SILVA, L. E. Projeto Pedagógico do Curso de Licenciatura em Ciências da UFPR Litoral: desafios e possibilidades para uma formação emancipatória. Revista Brasileira de Estudos Pedagógicos. Brasília, v. 94, n. 237, mai/ago 2013, p. 524-541.

SOUZA, V. C. Política de formação de professores para a educação básica - a questão da igualdade. Revista Brasileira de Educação, v. 19, n. 58, jul./set., 2014. 